\title{
2A and 2A-like Sequences: Distribution in Different Virus Species and Applications in Biotechnology
}

\author{
Juliana G. S. de Lima ${ }^{1,2}$ and Daniel C. F. Lanza ${ }^{1,2, *}$ \\ 1 Applied Molecular Biology Lab-LAPLIC, Department of Biochemistry, Federal University of Rio Grande do \\ Norte, Natal 59064-720, Brazil; julianagabriela91@gmail.com \\ 2 Postgraduate Program in Biochemistry, Federal University of Rio Grande do Norte, Natal 59064-720, Brazil \\ * Correspondence: danielclanza@gmail.com; Tel.: +55-84-3215-3416; Fax: +55-84-3215-3415
}

Citation: de Lima, J.G.S.; Lanza, D.C.F. 2A and 2A-like Sequences: Distribution in Different Virus Species and Applications in Biotechnology. Viruses 2021, 13, 2160. https://doi.org/10.3390/v13112160

Academic Editor: Craig E. Cameron

Received: 26 August 2021

Accepted: 22 September 2021

Published: 26 October 2021

Publisher's Note: MDPI stays neutral with regard to jurisdictional claims in published maps and institutional affiliations.

Copyright: (c) 2021 by the authors. Licensee MDPI, Basel, Switzerland. This article is an open access article distributed under the terms and conditions of the Creative Commons Attribution (CC BY) license (https:/ / creativecommons.org/licenses/by/ $4.0 /)$.

\begin{abstract}
A is an oligopeptide sequence that mediates a ribosome "skipping" effect and can mediate a co-translation cleavage of polyproteins. These sequences are widely distributed from insect to mammalian viruses and could act by accelerating adaptive capacity. These sequences have been used in many heterologous co-expression systems because they are versatile tools for cleaving proteins of biotechnological interest. In this work, we review and update the occurrence of 2A/2A-like sequences in different groups of viruses by screening the sequences available in the National Center for Biotechnology Information database. Interestingly, we reported the occurrence of 2A-like for the first time in 69 sequences. Among these, 62 corresponded to positive single-stranded RNA species, six to double stranded RNA viruses, and one to a negative-sense single-stranded RNA virus. The importance of these sequences for viral evolution and their potential in biotechnological applications are also discussed.
\end{abstract}

Keywords: 2A peptide; double-stranded RNA virus; positive-sense single-stranded RNA virus; Totiviridae; Picornaviridae

\section{Introduction}

2A and 2A-like sequences are oligopeptides with approximately 18-25 amino acids and can mediate a co-translation "cleavage" of polyproteins in eukaryotic cells. The "core" sequence at the $\mathrm{C}$-terminus of $2 \mathrm{~A}$, together with the $\mathrm{N}$-terminal proline of the downstream protein, contains the canonical motif- $(\mathrm{G} / \mathrm{H})_{1} \mathrm{D}_{2}(\mathrm{~V} / \mathrm{I})_{3} \mathrm{E}_{4} \mathrm{X}_{5} \mathrm{~N}_{6} \mathrm{P}_{7} \mathrm{G}_{8} \mathrm{P}_{9}$-involved in a ribosome "skipping" effect during translation, which separates two proteins without needing a proteinase $[1,2]$.

The 2A cleavage occurs between the $\mathrm{G}_{8}$ site at the upstream protein (P1) and the $\mathrm{P}_{9}$ site at the downstream protein (P2). During amino acid insertion into the protein, the $2 \mathrm{~A}$ sequence can cause a structural modification at the ribosome peptidyl-transferase center (PTC), making the ribosome "skip" the proline codon. It inhibits the formation of a glycineproline peptide bond because of the hydrolysis of the peptidyl (2A)-tRNAGly ester linkage, releasing the polypeptide from the translational complex [3,4]. In this way, the first amino acid, proline, of the downstream encoded protein, is specified by the third codon in the sequence of $\mathrm{P}_{7} \mathrm{G}_{8} \mathrm{P}_{9}$, and the $\mathrm{C}$-terminal amino acid of the upstream encoded protein is a glycine encoded by the second codon in that sequence $[5,6]$. This ribosome "skipping" effect is also referred to as "Stop-Carry On" or "StopGo" translation [6]. Thus, the ribosome activity does not depend on structural elements within the mRNA but a peptide sequence, differentiating this mechanism from the other forms of non-canonical mRNA processing. Because of this activity, the 2A and 2A-like sequences can be named CHYSELs (cis-acting hydrolase elements) [7].

Originally, the term " $2 \mathrm{~A}$ " was assigned to define a specific region of the genome of the foot-and-mouth disease virus (FMDV), a positive-sense single-stranded RNA (pssRNA) virus and member of the Picornaviridae family $[1,4,8-10]$. Similar sequences discovered in 
other viruses were named "2A-like." These sequences have been described in other Picornaviridae, such as Equine rhinitis $A$ virus and Porcine teschovirus-1, in other viruses of the Dicistroviridae and Iflaviviridae families [2], and even in the infectious myonecrosis virus (IMNV), a double-stranded RNA (dsRNA) virus belonging to the Totiviridae family [11].

From these first discoveries, the 2A and 2A-like proteolytic cleavage activities have been demonstrated in several eukaryotic systems in vitro and in vivo [2,12]. Because of their mechanism of action, some authors also refer to $2 \mathrm{~A}$ and $2 \mathrm{~A}$-like peptides as cis-acting hydrolase elements $[7,13]$.

In 2017, Yang et al. reviewed the 2A sequence structures and functions of Picornaviridae members [14]. The latest works analyzing 2A and 2A-like sequences, including viruses from other families, were conducted by Luke et al. in 2008, 2009, and 2014 and by Luke and Ryan in 2013 [2,15-17]. With advances in sequencing technology, in recent years, there has been a significant increase in the number of viral sequences added to the National Center for Biotechnology Information (NCBI) database. Therefore, the goal of this article was to introduce a new screening of $2 \mathrm{~A}$ and $2 \mathrm{~A}$-like sequences in viral genomes available from the NCBI database to revise the principal 2A and 2A-like sequences, describe their occurrence in different viral families, and discuss their potential applications in biotechnology.

\section{Materials and Methods}

The sequences used in this study were obtained from the viral databank (https:// www.ncbi.nlm.nih.gov/genome/viruses/, accessed on 9 January 2021). To find 2A/2A-like sequences, the viral genomes were aligned against some of the $2 \mathrm{~A} / 2 \mathrm{~A}$-like classical motifs (GDVEENPGP; GDVESNPGP; HDIETNPGP; GDVELNPGP; GDIELNPGP; GDIESNPGP; HDVEMNPGP) using the Blastp tool (https:/ / blast.ncbi.nlm.nih.gov/Blast.cgi, accessed on 9 January 2021) and the non-redundant protein sequences database (nr) only including viruses (taxid:10239). Search parameters were set to return a maximum of 500 sequences for each query. Repeated viral sequences were excluded from the analysis.

An active search was performed on the publication linked to the sequence annotation in the NCBI database to identify whether the sequences found had already been reported in the literature after the initial screening. If no report was found, an active search was performed using the Google Scholar search tool, with each respective virus name plus the word " $2 \mathrm{~A}$ " as keywords. If no articles reported the presence of $2 \mathrm{~A} / 2 \mathrm{~A}$-like in the query virus, we considered this finding novel.

\section{Results and Discussion}

\subsection{A/2A-Like Distribution on Viruses}

Table 1 shows the principal $2 \mathrm{~A}$ or $2 \mathrm{~A}$-like motifs that had their self-cleavage efficiencies tested in vitro, confirming that these sequences are widely distributed among the pssRNA and dsRNA viruses, ranging from insect to mammalian viruses. Luke et al. were the first to report this wide distribution and identified motifs similar to those found in the FMDV [2].

Table 1. Principal 2A/2A-like motifs described in literature and their cleavage efficiency.

\begin{tabular}{lllll}
\hline Virus & Family & Motif & Cleavage Efficiency & References \\
\hline Euprosterna elaeasa virus (EeV) & Alphatetraviridae & GDVEENPGP & $\sim 99 \%$ & {$[2,18]$} \\
Providence virus $($ PrV) & Alphatetraviridae & GDVESNPGP & $\sim 99 \%$ & {$[2]$} \\
Providence virus $(\mathrm{PrV})$ & Alphatetraviridae & GDIEKNPGP & $\sim 94 \%$ & {$[2]$} \\
Providence virus $(\mathrm{PrV})$ & Alphatetraviridae & GDVEKNPGP & $\sim 99 \%$ & {$[2]$} \\
Thosea asigna virus $(\mathrm{TaV})$ & Alphatetraviridae & GDVEENPGP & $\sim 99 \%$ & {$[1]$} \\
Acute bee paralysis virus (ABPV) & Dicistroviridae & GDVETNPGP & $\sim 94 \%$ & {$[1,2]$} \\
Cricket paralysis virus $(\mathrm{CrPV})$ & Dicistroviridae & GDVESNPGP & $\sim 90 \%$ & {$[1,2]$} \\
Drosophila C virus $(\mathrm{DCV})$ & Dicistroviridae & GDVETNPGP & $\sim 95 \%$ & {$[1]$} \\
Ectropis oblique picorna-like virus (EoPV) & Iflaviridae & GDVESNPGP & $\sim 99 \%$ & {$[2,19]$} \\
Ectropis oblique picorna-like virus (EoPV) & Iflaviridae & GDIESNPGP & $\sim 99 \%$ & {$[2,19]$} \\
Infectious flacherie virus $($ IFV) & Iflaviridae & AGIESNPGP & $\sim 99 \%$ & {$[1,2]$} \\
Perina nuda picorna-like virus (PnPV) & Iflaviridae & GDVESNPGP & $\sim 99 \%$ & {$[2,20]$} \\
\hline
\end{tabular}


Table 1. Cont.

\begin{tabular}{lllll}
\hline Virus & Family & Motif & Cleavage Efficiency & References \\
\hline Perina nuda picorna-like virus (PnPV) & Iflaviridae & GDIESNPGP & $\sim 99 \%$ & {$[2,20]$} \\
Encephalomyocarditis virus (EMCV) & Picornaviridae & HDIETNPGP & $\sim 91 \%$ & {$[1,8]$} \\
Equine rhinitis A virus (ERAV) & Picornaviridae & GDVESNPGP & $\sim 99 \%$ & {$[1,21]$} \\
Equine rhinitis B virus (ERBV-1) & Picornaviridae & GDVELNPGP & $\sim 99 \%$ & {$[2,22]$} \\
Foot-and-mouth disease virus (FMDV) & Picornaviridae & GDVESNPGP & $\sim 99 \%$ & {$[8,10]$} \\
Ljungan virus (LV) & Picornaviridae & GDVETNPGP & $\sim 99 \%$ & {$[2,23]$} \\
Porcine teschovirus 1 (PTV-1) & Picornaviridae & GDVEENPGP & $\sim 94 \%$ & {$[1,24]$} \\
Saffold virus (SAF-V) & Picornaviridae & HDVETNPGP & $\sim 99 \%$ & {$[2,25]$} \\
Theiler's murine encephalomyelitis virus (TMEV) & Picornaviridae & HDVEMNPGP & $\sim 99 \%$ & {$[10]$} \\
Bombyx mori reoviridae 1 (BmCPV-1) & Reoviridae & GDIESNPGP & $\sim 99 \%$ & {$[2,26]$} \\
Human reoviridae C (HurV-C) & Reoviridae & GDIELNPGP & $\sim 82 \%$ & {$[2]$} \\
New adult diarrhea virus (ADRV-N) & Reoviridae & ECIESNPGP & $\sim 97 \%$ & {$[2,27]$} \\
Operophtera brumata reoviridae 18 (OpbuCPV-18) & Reoviridae & GDVESNPGP & $\sim 99 \%$ & {$[2]$} \\
Porcine reoviridae A (Porv-C) & Reoviridae & GDVELNPGP & $\sim 89 \%$ & {$[1,2]$} \\
Infectious myonecrosis virus (IMNV) & Unassigned & GDVESNPGP & $\sim 99 \%$ & {$[2,11]$} \\
Infectious myonecrosis virus (IMNV) & Totiviridae & & {$[2,11]$} \\
\hline
\end{tabular}

The search for these motifs in the viral genomes available in the NCBI database revealed 69 sequences containing 2A-like motifs that had not been identified. Among these, 62 corresponded to pssRNA, six to dsRNA, and one to a negative-sense single-stranded RNA (nssRNA) virus. Additionally, 2A-like motifs, previously described in 102 sequences, were confirmed. All 2A/2A-like motifs and their respective species resulting from the search are described in Tables 2 and 3.

Table 2. Positive-sense single-stranded RNA virus containing 2A-like motifs.

\begin{tabular}{|c|c|c|c|}
\hline Accession Number & Virus & 2A Motif & Taxon \\
\hline \multirow{3}{*}{ YP_003620399.1 } & Providence virus- $2 \mathrm{~A}_{1}$ & GDVEKNPGP & \multirow{3}{*}{ Carmotetraviridae } \\
\hline & Providence virus- $-2 \mathrm{~A}_{2}$ & GDVESNPGP & \\
\hline & Providence virus-2 $\mathrm{A}_{3}$ & GDIEKNPGP & \\
\hline NP_066241.1 & Acute bee paralysis virus & GDVETNPGP & Dicistroviridae \\
\hline YP_009252204.1 & Anopheles C virus & GDVELNPGP & Dicistroviridae \\
\hline NP_647481.1 & $\overline{\text { Cricket paralysis virus }}$ & GDVESNPGP & Dicistroviridae \\
\hline NP_044945.1 & Drosophila C virus & GDVETNPGP & Dicistroviridae \\
\hline AMO03208.1 & Empeyrat virus & GDVELNPGP & Dicistroviridae \\
\hline YP_008888535.1 & $\overline{\text { Formica exsecta virus } 1}$ & GDIESNPGP & Dicistroviridae \\
\hline YP_009221981.1 & Goose dicistrovirus & GDVELNPGP & Dicistroviridae \\
\hline ASS83246.1 & Israeli acute paralysis virus & GDVEENPGP & Dicistroviridae \\
\hline NP_851403.1 & Kashmir bee virus & GDIELNPGP & Dicistroviridae \\
\hline YP_009011065.1 & Fusarium graminearum hypovirus 1 & HDVEKNPGP & Hypoviridae \\
\hline \multirow{2}{*}{ YP_009361829.1 } & $\overline{\text { Diamond back moth iflavirus-2 }-2 \mathrm{~A}_{1}}$ & GDVESNPGP & \multirow{2}{*}{ Iflaviridae } \\
\hline & $\overline{\text { Diamond back moth iflavirus }}-2 \mathrm{~A}_{2}$ & GDVESNPGP & \\
\hline \multirow{2}{*}{ NP_919029.1 } & 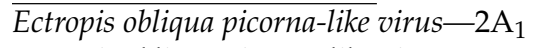 & GDVESNPGP & \multirow{2}{*}{ Iflaviridae } \\
\hline & Ectropis obliqua picorna-like virus-2 $\mathrm{A}_{2}$ & GDIESNPGP & \\
\hline \multirow{2}{*}{ NP_277061.1 } & Perina nuda virus- $2 \mathrm{~A}_{1}$ & GDVESNPGP & \multirow{2}{*}{ Iflaviridae } \\
\hline & Perina nuda virus-2 $\mathrm{A}_{2}$ & GDIESNPGP & \\
\hline YP_009010984.1 & Spodoptera exigua iflavirus 2 & GDVESNPGP & Iflaviridae \\
\hline NP_573542.1 & Euprosterna elaeasa virus & GDVEENPGP & Permutotetraviridae \\
\hline AAC97195.1 & Thosea asigna virus & GDVEENPGP & Permutotetraviridae \\
\hline \multirow{4}{*}{ AXF38648.1 } & Avihepatovirus sp. $-2 \mathrm{~A}_{1}$ & GDVESNPGP & \multirow{4}{*}{ Picornaviridae } \\
\hline & $\overline{\text { Avihepatovirus sp. }}-2 \mathrm{~A}_{2}$ & GDVESNPGP & \\
\hline & $\overline{\text { Avihepatovirus sp. }}-2 \mathrm{~A}_{3}$ & GDVEPNPGP & \\
\hline & Avihepatovirus sp. $-2 \mathrm{~A}_{4}$ & GDVESNPGP & \\
\hline AUX16868.1 & $\overline{\text { Avisivirus AVE052/AsV }}$ & GDIEENPGP & Picornaviridae \\
\hline
\end{tabular}


Table 2. Cont.

\begin{tabular}{|c|c|c|c|}
\hline Accession Number & Virus & 2A Motif & Taxon \\
\hline YP_009345900.1 & Bat crohivirus & GDIESNPGP & Picornaviridae \\
\hline YP_006607894.1 & $\begin{array}{l}\text { Bluegill picornavirus-2 } \mathrm{A}_{1} \\
\text { Bluegill picornavirus-2 } \mathrm{A}_{2}\end{array}$ & $\begin{array}{l}\text { GDVESNPGP } \\
\text { GDVEONPGP }\end{array}$ & Picornaviridae \\
\hline YP_006792625.1 & Bovine hungarovirus 1 & GDVELNPGP & Picornaviridae \\
\hline YP_009116874.1 & Bovine picornavirus & GDIESNPGP & Picornaviridae \\
\hline AQX17368.1 & Bovine rhinitis $B$ virus & GDIESNPGP & Picornaviridae \\
\hline ANN02879.1 & Bovine rhinitis B virus & GDIETNPGP & Picornaviridae \\
\hline YP_009352243.1 & Bovine rhinovirus 1 & GDVETNPGP & Picornaviridae \\
\hline QEQ92497.1 & Burpengary virus & GDVEQNPGP & Picornaviridae \\
\hline ACG61138.2 & Cardiovirus $D$ & HDIETNPGP & Picornaviridae \\
\hline AEJ86360.1 & Cardiovirus Hu/SIDS-347/DEU/2010 & HDIETNPGP & Picornaviridae \\
\hline YP_008992026.1 & $\begin{array}{l}\text { Carp picornavirus } 1-2 \mathrm{~A}_{1} \\
\text { Carp picornavirus } 1-2 \mathrm{~A}_{2}\end{array}$ & $\begin{array}{l}\text { GDVEQNPGP } \\
\text { GDVESNPGP }\end{array}$ & Picornaviridae \\
\hline QMI57967.1 & Chestnut teal aalivirus & GDVEENPGP & Picornaviridae \\
\hline YP_002956074.1 & $\overline{\text { Cosavirus } A}$ & GDIESNPGP & Picornaviridae \\
\hline YP_002956076.1 & Cosavirus $D$ & GDIETNPGP & Picornaviridae \\
\hline YP_009361830.1 & Cosavirus F & GDVEENPGP & Picornaviridae \\
\hline YP_009104360.1 & Crohivirus & GDIESNPGP & Picornaviridae \\
\hline YP_009345900.1 & Crohivirus B & GDIESNPGP & Picornaviridae \\
\hline \multirow{4}{*}{ YP_009026377.1 } & Duck picornavirus GL/12-2 $\mathrm{A}_{1}$ & GDVESNPGP & \multirow{4}{*}{ Picornaviridae } \\
\hline & Duck picornavirus GL/12-2 $\mathrm{A}_{2}$ & GDVEENPGP & \\
\hline & Duck picornavirus $\mathrm{GL} / 12-2 \mathrm{~A}_{3}$ & GDVEMNPGP & \\
\hline & Duck picornavirus GL/12-2 $\mathrm{A}_{4}$ & GDIEQNPGP & \\
\hline AAA43035.1 & Encephalomyocarditis virus & HDIETNPGP & Picornaviridae \\
\hline AKE44318.1 & Encephalomyocarditis virus & HDVETNPGP & Picornaviridae \\
\hline AGU38152.1 & Encephalomyocarditis virus & HDVELNPGP & Picornaviridae \\
\hline AFO66759.1 & Encephalomyocarditis virus type 2 & HDVETNPGP & Picornaviridae \\
\hline NP_653077.1 & Equine rhinitis B virus 1 & GDVELNPGP & Picornaviridae \\
\hline ANJ20934.1 & Equine rhinitis $B$ virus 2 & GDVESNPGP & Picornaviridae \\
\hline ANJ20932.1 & Erbovirus $A$ & GDVESNPGP & Picornaviridae \\
\hline ANJ20933.1 & Erbovirus A & GDVELNPGP & Picornaviridae \\
\hline \multirow{2}{*}{ YP_009423853.1 } & Falcon picornavirus-2 $\mathrm{A}_{1}$ & GDVEENPGP & \multirow{2}{*}{ Picornaviridae } \\
\hline & Falcon picornavirus- $2 \mathrm{~A}_{2}$ & GDVELNPGP & \\
\hline \multirow[b]{2}{*}{ AHL26986.1 } & Fathead minnow picornavirus-2 $\mathrm{A}_{1}$ & GDVEQNPGP & \multirow[b]{2}{*}{ Picornaviridae } \\
\hline & Fathead minnow picornavirus-2 $\mathrm{A}_{2}$ & GDVESNPGP & \\
\hline AYJ71467.2 & Feline hunnivirus & GDVELNPGP & Picornaviridae \\
\hline AAT01719.1 & Foot-and-mouth disease virus-type A & GDVESNPGP & Picornaviridae \\
\hline AFM56034.1 & Foot-and-mouth disease virus-type $\mathrm{O}$ & GDVESNPGP & Picornaviridae \\
\hline AAT01787.1 & Foot-and-mouth disease virus - type SAT 1 & GDVESNPGP & Picornaviridae \\
\hline AFE84748.1 & Foot-and-mouth disease virus_-type SAT 2 & GDVESNPGP & Picornaviridae \\
\hline AAT01795.1 & Foot-and-mouth disease virus - type SAT 3 & GDVESNPGP & Picornaviridae \\
\hline AIB06813.1 & Genet fecal theilovirus & HDVEMNPGP & Picornaviridae \\
\hline YP_009026376.1 & Human cosavirus & GDIETNPGP & Picornaviridae \\
\hline AFJ04537.1 & Human cosavirus A20 & GDIESNPGP & Picornaviridae \\
\hline YP_002956075.1 & Human cosavirus B & HDIETNPGP & Picornaviridae \\
\hline ADF28539.1 & Human TMEV-like cardiovirus & HDIETNPGP & Picornaviridae \\
\hline AMT85188.1 & Hunnivirus & GDVEENPGP & Picornaviridae \\
\hline YP_009118270.1 & Lesavirus 2 & GDIEPNPGP & Picornaviridae \\
\hline ACJ48052.1 & Ljungan virus & GDVEENPGP & Picornaviridae \\
\hline \multirow{2}{*}{ AVX29482.1 } & Marmot mosavirus-2 $\mathrm{A}_{1}$ & GDVETNPGP & \multirow{2}{*}{ Picornaviridae } \\
\hline & Marmot mosavirus-2 $\mathrm{A}_{2}$ & GDVETNPGP & \\
\hline ANX14418.1 & Mengo virus & HDVETNPGP & Picornaviridae \\
\hline YP_009361319.1 & Miniopterus schreibersii picornavirus 1 & GDVEENPGP & Picornaviridae \\
\hline AWC68493.1 & Mischivirus B & GDIEENPGP & Picornaviridae \\
\hline YP_009026384.1 & Mosavirus A2 & GDVESNPGP & Picornaviridae \\
\hline YP_009109563.1 & Norway rat hunnivirus & GDVELNPGP & Picornaviridae \\
\hline ADO85550.2 & Ovine hungarovirus & GDVELNPGP & Picornaviridae \\
\hline AIU94297.1 & Pasivirus $A$ & GDVEQNPGP & Picornaviridae \\
\hline
\end{tabular}


Table 2. Cont.

\begin{tabular}{|c|c|c|c|}
\hline Accession Number & Virus & 2A Motif & Taxon \\
\hline SNQ28005.1 & Pasivirus A & GDIEQNPGP & Picornaviridae \\
\hline APA29021.1 & Picornaviridae sp. rodent & GDVELNPGP & Picornaviridae \\
\hline ADN52625.1 & Porcine encephalomyocarditis virus & HDIETNPGP & Picornaviridae \\
\hline AAK12398.1 & Porcine teschovirus 1 & GDVEENPGP & Picornaviridae \\
\hline AAK12413.1 & Porcine teschovirus 10 & GDVEENPGP & Picornaviridae \\
\hline AAK12390.1 & Porcine teschovirus 11 & GDVEENPGP & Picornaviridae \\
\hline AAK12381.1 & Porcine teschovirus 2 & GDVEENPGP & Picornaviridae \\
\hline AAK12382.1 & Porcine teschovirus 3 & GDVEENPGP & Picornaviridae \\
\hline AGB67759.1 & Porcine teschovirus 4 & GDVEENPGP & Picornaviridae \\
\hline АCT66681.1 & Porcine teschovirus 5 & GDVEENPGP & Picornaviridae \\
\hline AAK12409.1 & Porcine teschovirus 6 & GDVEENPGP & Picornaviridae \\
\hline AAK12386.1 & Porcine teschovirus 7 & GDVEENPGP & Picornaviridae \\
\hline AAK12388.1 & Porcine teschovirus 9 & GDVEENPGP & Picornaviridae \\
\hline QHX40840.1 & Porcine teschovirus 22 & GDIEENPGP & Picornaviridae \\
\hline ACD67870.1 & $\overline{\text { Rat theilovirus } 1}$ & HDVETNPGP & Picornaviridae \\
\hline AWK02689.1 & Rattus tanezumi hunnivirus & GDVEENPGP & Picornaviridae \\
\hline \multirow{2}{*}{ AWK02688.1 } & 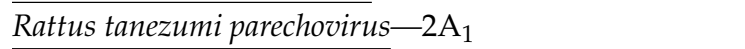 & GDVEENPGP & \multirow{2}{*}{ Picornaviridae } \\
\hline & $\overline{\text { Rattus tanezumi parechovirus }}-2 \mathrm{~A}_{2}$ & GDVEENPGP & \\
\hline ACO92353.1 & $\overline{\text { Saffold virus }}$ & HDIETNPGP & Picornaviridae \\
\hline YP_001210296.2 & Saffold virus & HDVETNPGP & Picornaviridae \\
\hline APZ85840.1 & Senecavirus A & GDIETNPGP & Picornaviridae \\
\hline AHW57724.1 & Sikhote-Alin virus & HDVEMNPGP & Picornaviridae \\
\hline AUK47911.1 & Swine pasivirus SPaV1/US/17-50816IA60467-1/2001 & GDVEQNPGP & Picornaviridae \\
\hline BAU71153.1 & Swine picornavirus & GDVEENPGP & Picornaviridae \\
\hline NP_653143.1 & Teschovirus A & GDVEENPGP & Picornaviridae \\
\hline ACG55799.1 & Theiler's encephalomyelitis virus & HDVETNPGP & Picornaviridae \\
\hline BAC58035.1 & Theiler's-like virus of rats & HDVETNPGP & Picornaviridae \\
\hline AIY68187.1 & Tortoise picornavirus & GDVEVNPGP & Picornaviridae \\
\hline AIY68186.1 & Tortoise picornavirus & GDVEQNPGP & Picornaviridae \\
\hline ACG55801.1 & Vilyuisk human encephalomyelitis virus & HDVEMNPGP & Picornaviridae \\
\hline AVM87411.1 & Yili teratoscincus roborowskii picornavirus 2 & GDVEQNPGP & Picornaviridae \\
\hline YP_009329817.1 & $\overline{\text { Bivalve RNA virus G1 }}$ & GDVETNPGP & Unassigned Dicistroviridae \\
\hline \multirow{2}{*}{ QNL09596.1 } & Clinch dicistro-like virus $2-2 A_{1}$ & GDVEMNPGP & \multirow{2}{*}{ Unassigned Dicistroviridae } \\
\hline & $\overline{\text { Clinch dicistro-like virus } 2-2 A_{2}}$ & GDVETNPGP & \\
\hline QJI52079.1 & $\overline{\text { Dicistroviridae sp. }}$ & GDVEMNPGP & Unassigned Dicistroviridae \\
\hline AYQ66681.1 & 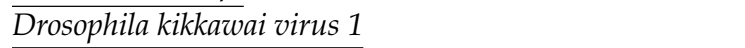 & GDVELNPGP & Unassigned Dicistroviridae \\
\hline YP_009336571.1 & Hubei diptera virus 1 & GDVELNPGP & Unassigned Dicistroviridae \\
\hline YP_009336583.1 & Hubei picorna-like virus 16 & GDVELNPGP & Unassigned Dicistroviridae \\
\hline YP_009336853.1 & $\overline{\text { Hubei picorna-like virus } 17}$ & GDVELNPGP & Unassigned Dicistroviridae \\
\hline QKF95572.1 & Leibnitzia anandria dicistrovirus & GDIEENPGP & Unassigned Dicistroviridae \\
\hline AXA52579.1 & Linepithema humile virus 1 & GDIELNPGP & Unassigned Dicistroviridae \\
\hline QIU80542.1 & Phenacoccus solenopsis virus & GDIEENPGP & Unassigned Dicistroviridae \\
\hline YP_009336743.1 & Wenling crustacean virus 3 & GDVEENPGP & Unassigned Dicistroviridae \\
\hline YP_009333180.1 & $\overline{\text { Wenling picorna-like virus } 2}$ & GDIELNPGP & Unassigned Dicistroviridae \\
\hline YP_009342327.1 & Wuhan insect virus 11 & GDIEANPGP & Unassigned Dicistroviridae \\
\hline YP_009329857.1 & $\overline{\text { Beihai hepe-like virus } 4}$ & GDIESNPGP & Unassigned Hepeviridae \\
\hline QDY81493.1 & 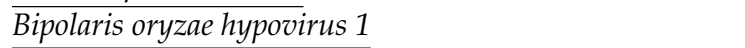 & GDVEANPGP & Unassigned Hypoviridae \\
\hline YP_009337372.1 & $\overline{\text { Hubei picorna-like virus } 43}$ & GDIESNPGP & Unassigned Iflaviridae \\
\hline \multirow{2}{*}{ QKN89050.1 } & Iflaviridae sp.-2 $\mathrm{A}_{1}$ & GDVESNPGP & \multirow{2}{*}{ Unassigned Iflaviridae } \\
\hline & Iflaviridae sp. $-2 \mathrm{~A}_{2}$ & GDIESNPGP & \\
\hline AWK77896.1 & Perth bee virus 3 & GDVETNPGP & Unassigned Iflaviridae \\
\hline \multirow[t]{2}{*}{ YP_009336821.1 } & Wenzhou picorna-like virus 49 & HDVELNPGP & \multirow[t]{2}{*}{ Unassigned Iflaviridae } \\
\hline & Guangdong spotted longbarbel catfish picornavirus- $-2 A_{1}$ & GDVEENPGP & \\
\hline \multirow[t]{2}{*}{ AVM87450.1 } & Guangdong spotted longbarbel catfish picornavirus-2 $2 \mathrm{~A}_{2}$ & GDIESNPGP & \multirow[t]{2}{*}{ Unassigned Picornavirales } \\
\hline & Guangdong spotted longbarbel catfish picornavirus-2A & GDVERNPGP & \\
\hline ASG92543.1 & Picornavirales Q_sR_OV_036 & GDVEANPGP & Unassigned Picornavirales \\
\hline
\end{tabular}


Table 2. Cont.

\begin{tabular}{|c|c|c|c|}
\hline Accession Number & Virus & 2A Motif & Taxon \\
\hline ASG92538.1 & Picornavirales Q_sR_OV_042 & GDIEENPGP & Unassigned Picornavirales \\
\hline ATY47693.1 & Picornavirales sp. & GDVEENPGP & Unassigned Picornavirales \\
\hline ATY47707.1 & $\overline{\text { Picornavirales sp. }}$ & GDVELNPGP & Unassigned Picornavirales \\
\hline AWK02666.1 & $\overline{\text { Rhinolophus sinicus picornavirus }}$ & GDIEENPGP & Unassigned Picornavirales \\
\hline QQP18688.1 & Soybean thrips picorna-like virus 7 & GDVETNPGP & Unassigned Picornavirales \\
\hline AWK02669.1 & Suncus murinus picornavirus & GDVETNPGP & Unassigned Picornavirales \\
\hline AWK77886.1 & Victoria bee virus 1 & GDVETNPGP & Unassigned Picornavirales \\
\hline AWK77887.1 & Victoria bee virus 2 & GDIETNPGP & Unassigned Picornavirales \\
\hline AVM87443.1 & Wenling thamnaconus septentrionalis picornavirus & GDIESNPGP & Unassigned Picornavirales \\
\hline \multirow[t]{2}{*}{ AVM87419.1 } & Western African lungfish picornavirus & GDVEENPGP & Unassigned Picornavirales \\
\hline & Wuhan carp picornavirus-2 $2 \mathrm{~A}_{1}$ & GDVESNPGP & \\
\hline \multirow[t]{2}{*}{ AVM87438.1 } & $\overline{\text { Wuhan carp picornavirus }}-2 \mathrm{~A}_{2}$ & GDVESNPGP & Unassigned Picornavirales \\
\hline & $\overline{\text { Wuhan carp picornavirus }}-2 \mathrm{~A}_{3}$ & GDVESNPGP & \\
\hline ANN02882.1 & $\overline{\text { Bovine rhinitis B virus } 5}$ & GDVETNPGP & Unassigned Picornaviridae \\
\hline AQM40272.1 & Human cosavirus (Cosavirus-zj-1) & GDVEENPGP & Unassigned Picornaviridae \\
\hline AWG94399.1 & Human cosavirus $E / D$ & GDVEENPGP & Unassigned Picornaviridae \\
\hline AVX29481.1 & Marmot cardiovirus & HDVETNPGP & Unassigned Picornaviridae \\
\hline AWK02672.1 & Niviventer confucianus hunnivirus & GDVELNPGP & Unassigned Picornaviridae \\
\hline AFV31450.1 & Parechovirus-like virus & GDVEQNPGP & Unassigned Picornaviridae \\
\hline QBH68005.1 & Parechovirus sp. QAPp32 & GDVEENPGP & Unassigned Picornaviridae \\
\hline \multirow[t]{2}{*}{ QKEE55061.1 } & Picornaviridae sp. & GDIEENPGP & Unassigned Picornaviridae \\
\hline & $\overline{\text { Picornaviridae sp. }}-2 \mathrm{~A}_{1}$ & GDVESNPGP & \\
\hline \multirow[t]{2}{*}{ QKE55028.1 } & $\overline{\text { Picornaviridae sp. }}-2 \mathrm{~A}_{2}$ & GDVEQNPGP & Unassigned Picornaviridae \\
\hline & $\overline{\text { Picornaviridae sp. }}-2 \mathrm{~A}_{3}$ & GDVESNPGP & \\
\hline \multirow[t]{2}{*}{ QIM74091.1 } & $\overline{\text { Picornaviridae sp. }}$ & HDVETNPGP & Unassigned Picornaviridae \\
\hline & 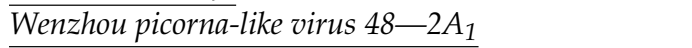 & GDIEENPGP & \\
\hline \multirow[t]{2}{*}{ YP_009336671.1 } & $\overline{\text { Wenzhou picorna-like virus } 48-2 A_{2}}$ & GDIESNPGP & Unassigned Picornaviridae \\
\hline & $\overline{\text { Wenzhou picorna-like virus } 48-2 A_{3}}$ & GDIEENPGP & \\
\hline AZT88626.1 & Aspergillus homomorphus yadokarivirus 1 & GDIEENPGP & Unassigned pssRNA \\
\hline APG77930.1 & Beihai picorna-like virus 76 & GDVETNPGP & Unassigned pssRNA \\
\hline YP_009333551.1 & $\overline{\text { Beihai picorna-like virus } 85}$ & GDVETNPGP & Unassigned pssRNA \\
\hline AYN75548.1 & Halhan virus 1 & GDVEQNPGP & Unassigned pssRNA \\
\hline AZT88627.1 & Penicillium digitatum yadokarivirus 1 & GDVETNPGP & Unassigned pssRNA \\
\hline QOI17269.1 & Picoa juniperi yado-kari virus 1 & GDIESNPGP & Unassigned pssRNA \\
\hline QHD64758.1 & Plasmopara viticola lesion associated yadokari virus 1 & GDIEENPGP & Unassigned pssRNA \\
\hline QIJ25855.1 & Warroolaba Creek virus 2 & GDVETNPGP & Unassigned pssRNA \\
\hline AVD68673.2 & Yado-kari virus 2 & GDVEENPGP & Unassigned pssRNA \\
\hline
\end{tabular}

Underlined names correspond to sequences that had no 2A sequence described before this study.

Table 3. Double-stranded RNA viruses identified in this study containing 2A-like motifs.

\begin{tabular}{llll}
\hline Accession Number & Virus & 2A Motif & Taxon \\
\hline AAU88188.1 & Adult diarrhea virus & ECIESNPGP & Reoviridae \\
BAB20437.1 & Bombyx mori cypovirus 1 & GDIESNPGP & Reoviridae \\
BAO73973.1 & Bovine rotavirus C & GDVELNPGP & Reoviridae \\
AAO32344.1 & Dendrolimus punctatus cypovirus 1 & GDVESNPGP & Reoviridae \\
BAU80889.1 & Human rotavirus C & GDIELNPGP & Reoviridae \\
AAK73524.1 & Lymantria dispar cypovirus 1 & GDVESNPGP & Reoviridae \\
ABB17215.1 & Operophtera brumata cypovirus 18 & GDVELNPGP & Reoviridae \\
BAV31546.1 & Porcine rotavirus C & GDVELNPGP & Reoviridae \\
QBJ02264.1 & Porcine rotavirus H & GDIESNPGP & Reoviridae \\
AQX34666.1 & Rotavirus I & GDIEENPGP & Uniridae \\
CCD33025.1 & Aspergillus foetidus slow virus 2 & GDigned dsRNA \\
YP_009272910.1 & Fusarium poae mycovirus 2 & GDIEENPGP & Unassigned dsRNA \\
YP_009182156.1 & Penicillium aurantiogriseum asp-foetidus like virus 1 & GDVELNPGP \\
YP_009342431.1 & Wuhan insect virus 31-2A 1 & Unassigned dsRNA \\
YP_003934933.1 & Wuhan insect virus 31-2A & GDVERNPGP & Unassigned Totiviridae \\
\hline
\end{tabular}


Table 3. Cont.

\begin{tabular}{llll}
\hline Accession Number & Virus & 2A Motif & Taxon \\
\hline YP_009256208.1 & Golden shiner totivirus & GDIESNPGP & Unassigned Totiviridae \\
AIC34742.2 & Penaeid shrimp infectious myonecrosis virus_-2A 1 Genes & GDVESPG & Unassigned Totiviridae \\
YP_009337085.1 & Penaeid shrimp infectious myonecrosis virus_-2A 2 & GDVEENPGP & Unassigned Totiviridae \\
YP_009333269.1 & Wenling toti-like virus 2 & GDIETNPGP & Unassigned Totiviridae \\
\hline
\end{tabular}

Underlined names correspond to new findings.

\section{2. pssRNA Viruses}

Here, we registered 62 new 2A-like notifications in pssRNA viruses, as presented in Table 2 (underlined). The positions in each respective genome are shown in Figure 1.

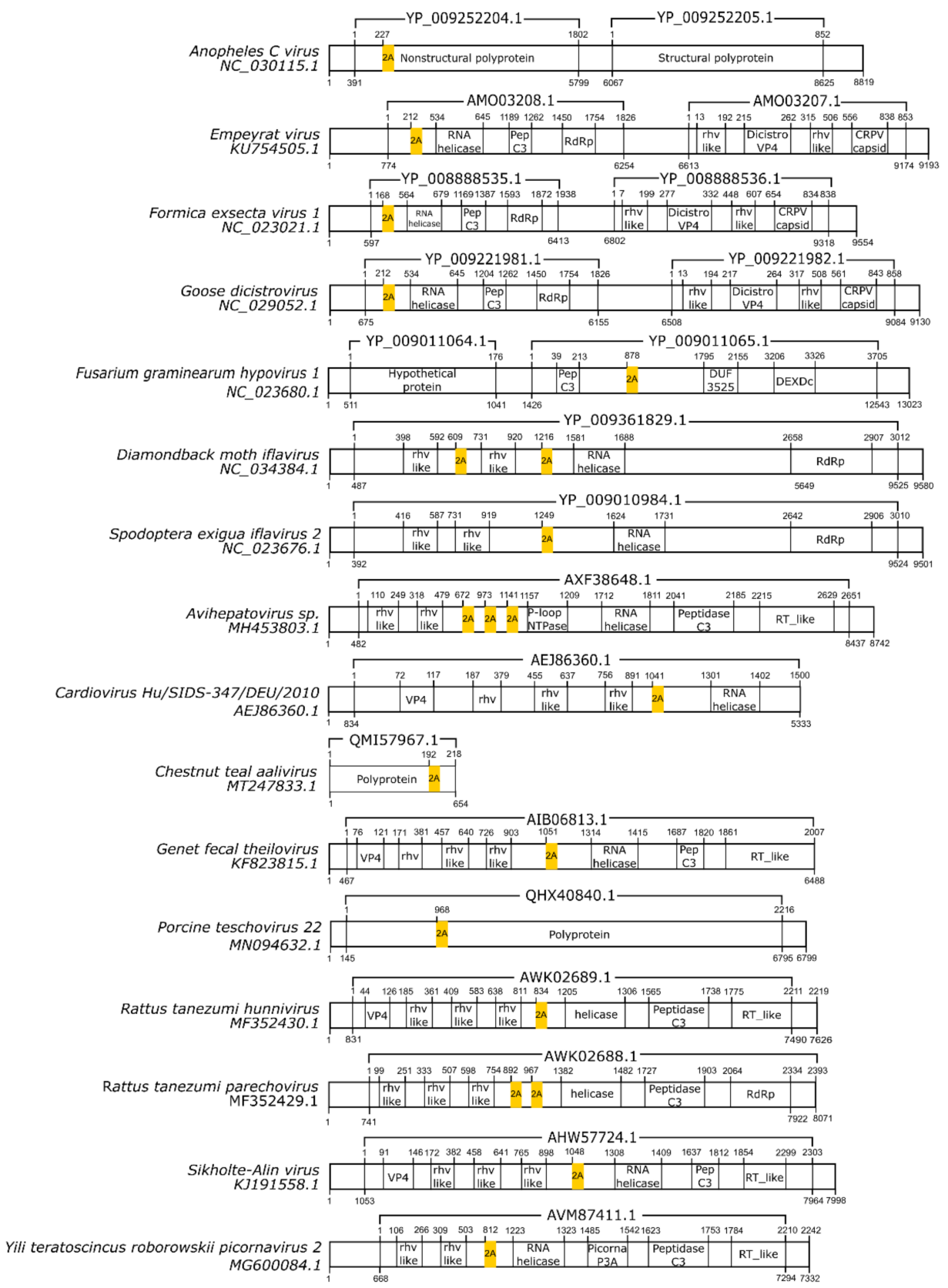

Part 1

Figure 1. Cont. 


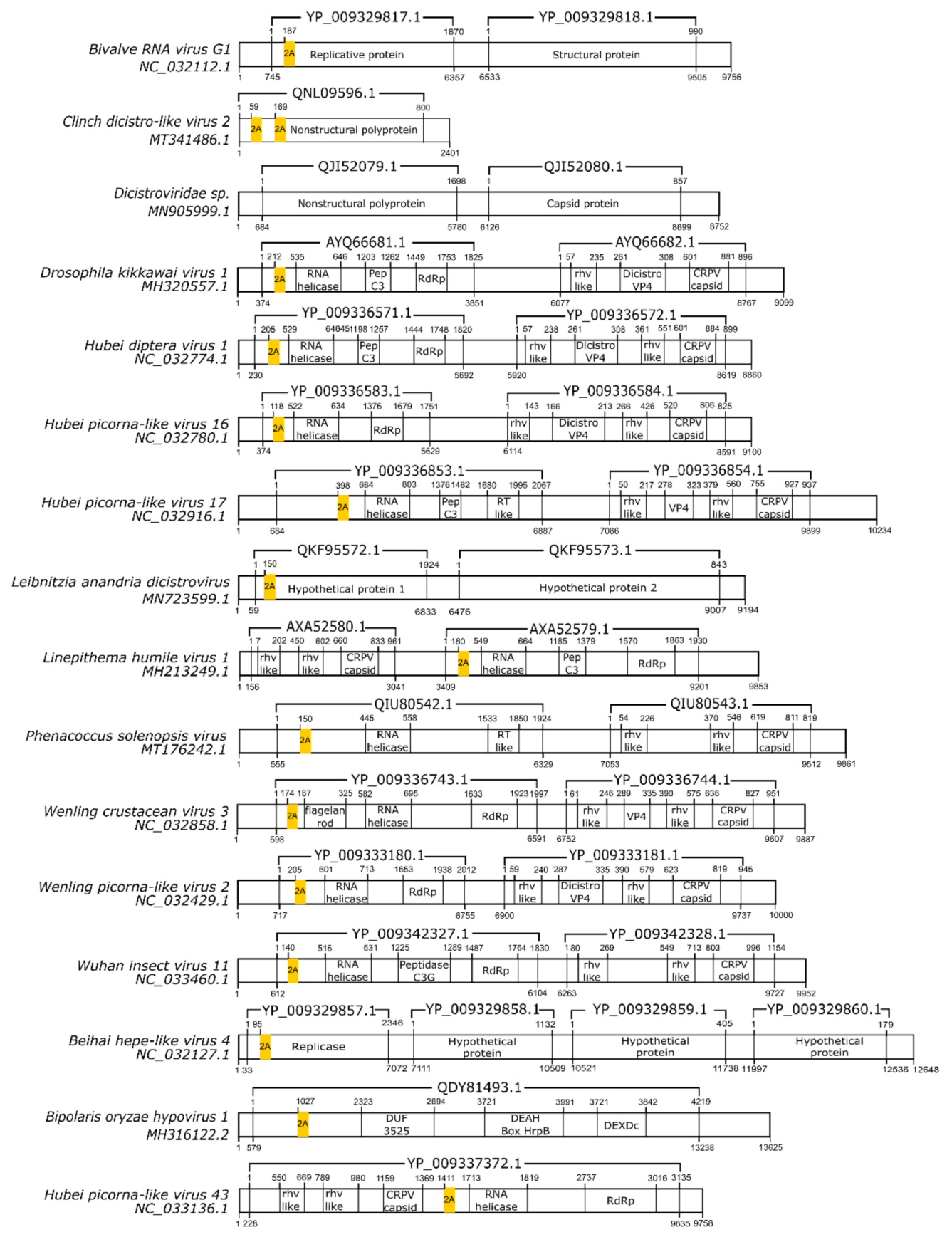

Part 2

Figure 1. Cont. 


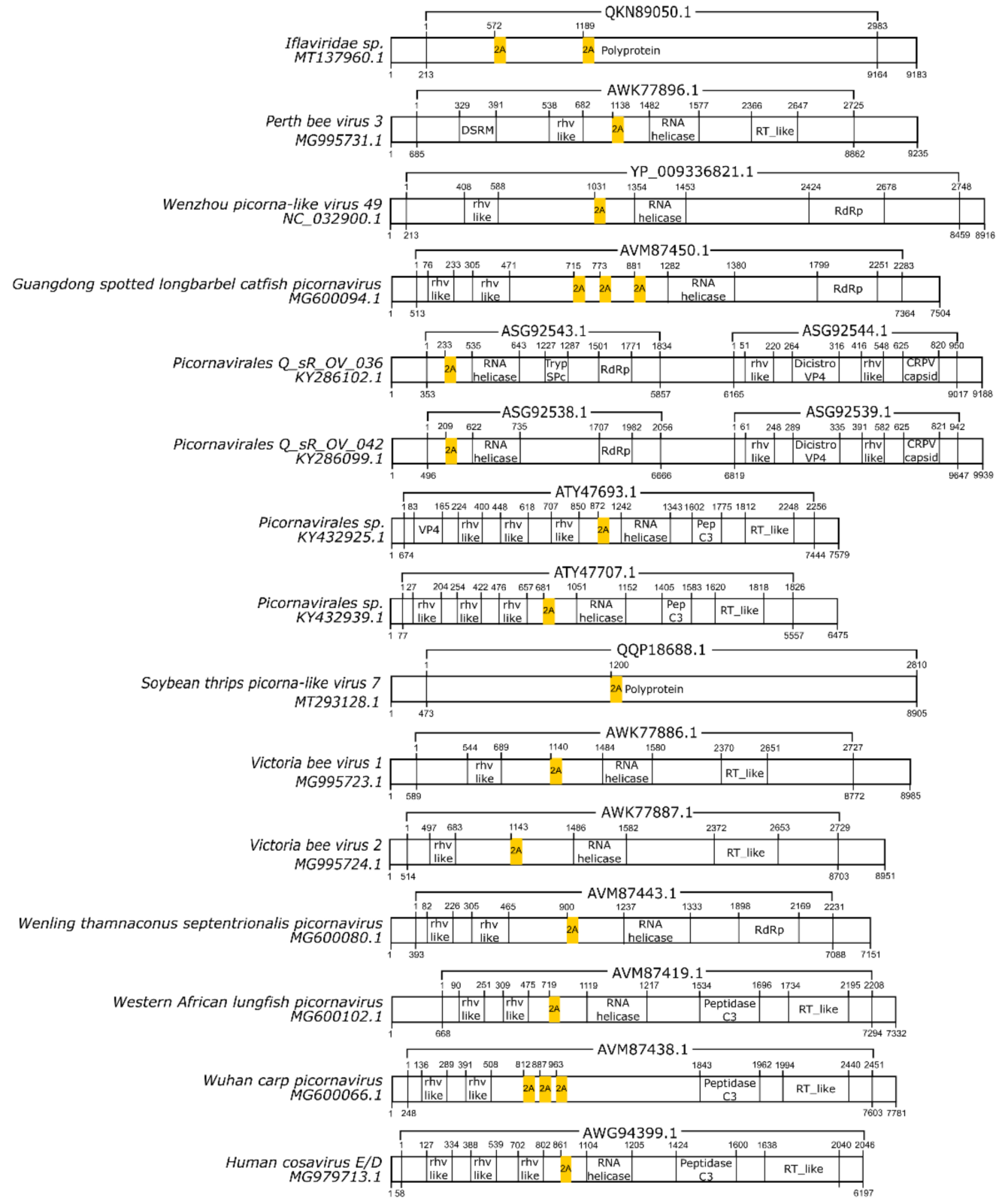

Part 3

Figure 1. Cont. 


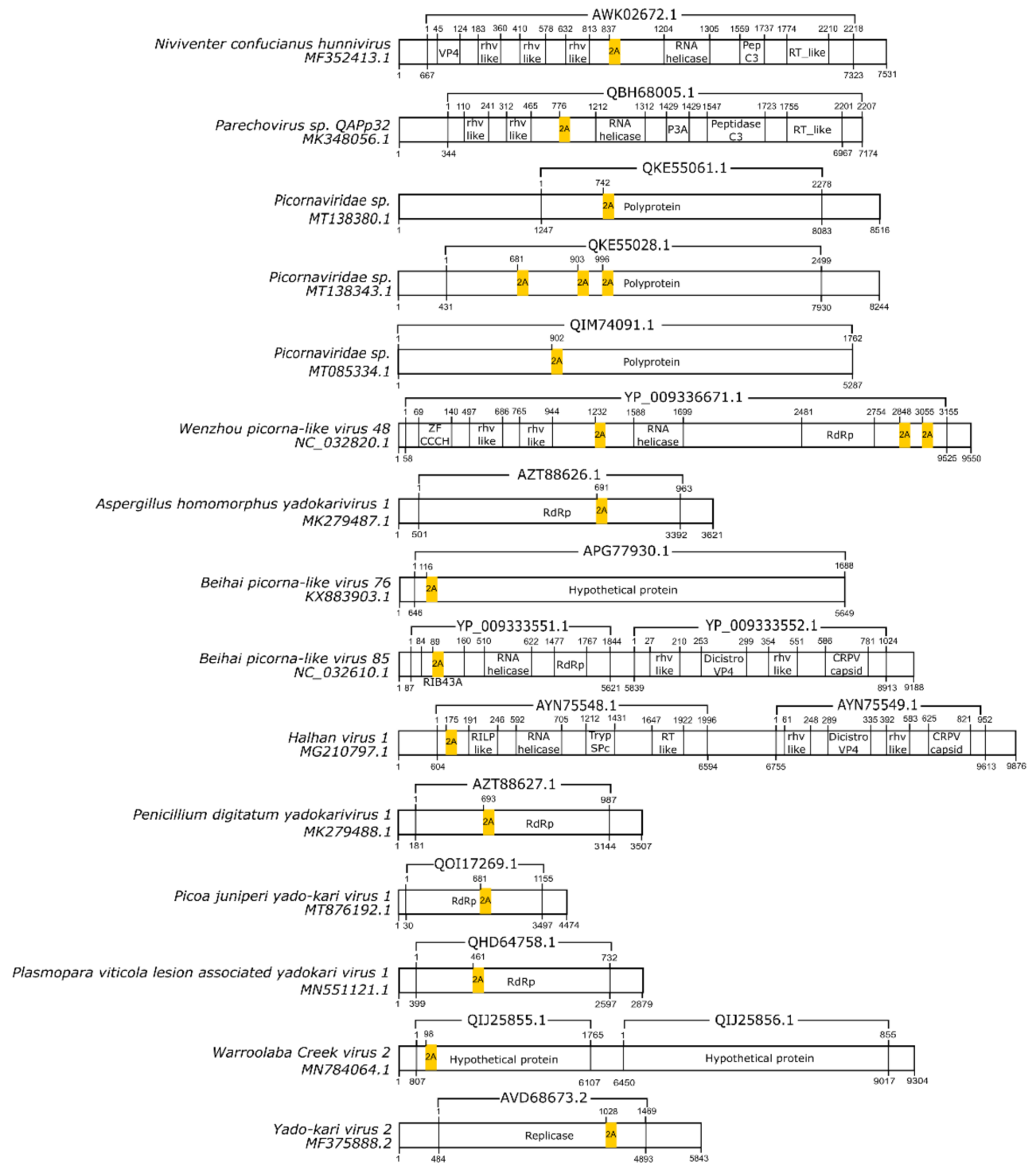

Part 4

Figure 1. Schematic representation of positive-sense single-strand RNA virus sequences. Schematic representations of pssRNA virus sequences showing the location of each respective 2A-like (yellow rectangles). The nucleotide positions and size of each predicted polypeptide are represented by the numbers below and above the bars, respectively. The annotations of each viral sequence were included according to the NCBI. The nucleotide and protein accession numbers are presented forward and above each scheme, respectively. Representations of each genome are not in scale. This figure is presented in four parts.

In most pssRNA viruses, 2A/2A-like segments are used in primary polypeptide processing. The pssRNA viruses commonly possess one $2 \mathrm{~A} / 2 \mathrm{~A}$-like sequence, but some viruses have two, three, or even four motifs (Table 2). Many of them are members of the order Picornavirales, such as Picornaviridae, Dicistroviridae, and Iflaviridae. Currently, the Picornaviridae family has 63 assigned genera [28], but 2A/2A-like sequences have been found in viruses assigned or tentatively assigned to 15 genera: Aphthovirus, Avihepatovirus, Cardiovirus, Cosavirus, Crohivirus, Erbovirus, Hunninvirus, Limnipivirus, Mischivirus, Mosavirus, Parechovirus, Pasivirus, Senecavirus, Teschovirus, and Torchivirus.

In aphthoviruses and cardioviruses, the 2A-like region self-cleaves at its own Cterminus, meaning that the $2 \mathrm{~A}$-like polypeptide remains as a C-terminal extension of 
the upstream polyprotein (P1) until it is removed by secondary proteinase cleavage $[8,9]$. However, in parechoviruses, the 2A-like region has no protease or protease-like activity, and its apparent function is to alter host cell metabolism because it possesses a high homology to cellular protein H-rev107 that regulates cell proliferation (H-box 2A) [29].

In insect Iflaviruses, the 2A-like sequence separates the capsid and replicative protein domains. The Dicistroviridae family is composed of the Aparavirus, Cripavirus, and Triatovirus genera, in which the 2A-like sequences occur at the $\mathrm{N}$-terminal region of the replicative protein open reading frame $(\mathrm{ORF})[2,14]$.

Members of the Permutotetraviridae and Carmotetraviridae families (previously Tetraviridae), Thosea asigna virus and Euprosterna elaeasa virus, encode a 2A-like sequence at the $\mathrm{N}$-terminus of the structural ORF [1]. The Providence virus has three 2A-like sequences, $2 \mathrm{~A}_{2}$ and $2 \mathrm{~A}_{3}$, located in the capsid protein precursor (VCAP), and $2 \mathrm{~A}_{1}$ at the N-terminus of the p130 ORF, which encodes the viral replicase [30].

\section{3. dsRNA Viruses}

Among the dsRNA viruses, 2A-like sequences not yet reported were found in six species. The new 2A-like sequences are underlined in Table 3, and their localization inside the genome is schematized in Figure 2.

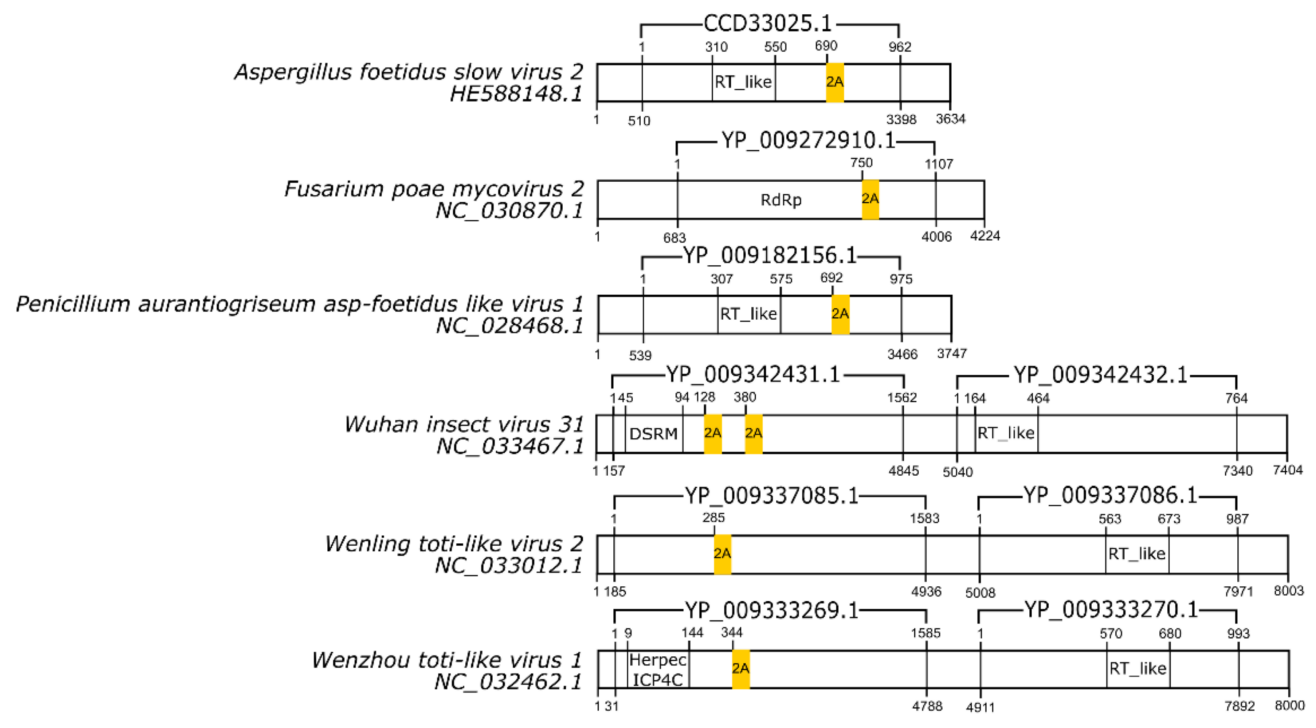

Figure 2. Schematic representation of double-stranded RNA virus sequences. Schematic representations of dsRNA virus sequences showing the location of each respective 2A-like (yellow rectangles). The nucleotide positions and size of each predicted polypeptide are represented by the numbers below and above the bars, respectively. The annotations of each viral sequence were made according to the information available at the NCBI. The nucleotide and protein accession numbers are located forward and above each scheme, respectively. Representations of each genome are not in scale.

In double-stranded viruses, 2A-like sequences are present in two families: Totiviridae and Reoviridae. In Totiviridae, 2A-like sequences are distributed in all representatives of the IMNV-like group [31]. These viruses predominantly infect arthropods, such as penaeid shrimp [32], mosquitoes [33,34], and the fruit fly Drosophila melanogaster [35], except for the golden shiner Totivirus that infects the fish Notemigonus crysoleucas [36]. The genome of IMNV-like viruses is composed of two ORFs, and the 2A-like sequences separate an RNA-binding protein of other putative proteins in ORF1 [37].

In the Reoviridae family, 2A-like sequences are found in cypoviruses and rotaviruses with 2A-like sequences in one of the segments encoding a non-structural protein. In Operophtera brumata cypovirus 18 and Bombyx mori cypovirus 1, 2A-like sequences occur within segment 5 . In type $C$ rotaviruses, $2 \mathrm{~A}$-like sequences link the ssRNA-binding protein NSP3 to dsRNA-binding protein (dsRBP). In porcine and human rotavirus $\mathrm{C}$, the 2A-like 
sequences are present at segment 6 , although in the adult diarrhea virus, the sequence appears in segment $5[1,2]$. All cypoviruses and rotaviruses possess only one 2A-like sequence (Table 3$)$.

\section{4. nssRNA Virus}

Surprisingly, one 2A-like motif (GDIEQNPGP) was found in a tentatively assigned virus of the Bunyaviridae family (Accession number: APG79245.1). This motif is located in the RNA-dependent RNA polymerase (RdRp) sequence (Figure 3). This is the first report of a 2A-like sequence in a nssRNA virus.

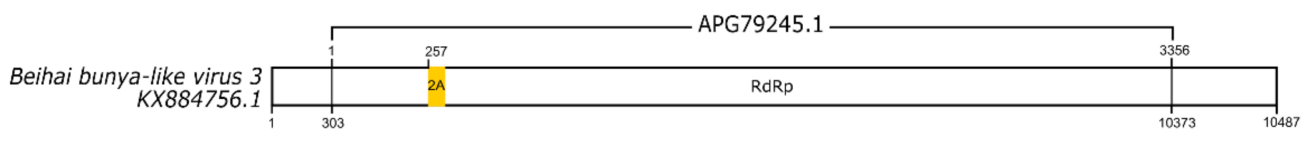

Figure 3. Schematic representation of a negative-sense single-strand RNA virus sequence. Schematic representations of nssRNA virus sequence showing the location of its respective 2A-like sequence (yellow rectangle). The nucleotide positions and size of the predicted polypeptide are represented by the numbers below and above the bars, respectively. The annotations of the viral sequence were made according to NCBI. The nucleotide and protein accession numbers are located forward and above the scheme, respectively. Representation of the genome are not to scale.

\subsection{A/2A-Likes Sequences and Viral Evolution}

Previous studies concerning RNA viruses and 2A-like peptides have reported that these sequences emerged independently during the evolution of viral families $[2,14]$. However, in a previous study [31], we showed sequences very similar to functional 2A-like sequences in some RNA viruses that could be the precursors of $2 \mathrm{~A}$ sequences.

In particular, RNA viruses depend on the activity of RNA-dependent RNA polymerases. These enzymes have a significant error rate $\left(10^{-3}\right.$ to $10^{-5}$ mutations per inserted nucleotide) because they do not have exonucleotide review activity [38]. This results in a high degree of genetic heterogeneity in populations of RNA viruses, which are believed to favor adaptability to different environments and hosts [39]. Considering this, the 2A/2A-like sequences could have emerged by subsequent mutation events that ended in a cleavage function, providing the advantage of releasing more than one protein from the same ORF. Therefore, this could directly impact viral adaptation potential and viral infection mechanisms to favor their fitness in complex multicellular systems [31].

Yang et al. also suggested that picornaviruses with more complex infection mechanisms than other viruses of the same family have more than one 2A-like sequence in their genomes [14]. Taking this evidence into account, it seems that 2A/2A-like sequences may be a key element in viral genome evolution and, once acquired, its loss of function may impact virus effectivity.

\subsection{Biotechnology Applications}

Various approaches have been employed to co-express multiple proteins in cells, including the use of internal ribosomal entry site (IRES) elements [40,41], dual promoter systems [42,43], and transfection of multiple vectors [44]. Each of these is associated with several limitations, such as uneven or unreliable protein expression levels, silencing of some promoters [45,46], and increased toxicity to cells (with multiple transfections) [47].

Co-expression systems, including $2 \mathrm{~A} / 2 \mathrm{~A}$-like peptides, could be an alternative strategy for expressing multiple genes under the control of a single promoter. These constructs could have the additional advantage of producing proteins at near-stoichiometric levels, unlike IRES-mediated polycistronic expression, where ribosomes are independently recruited at distinct regions with the mRNA $[1,4,48,49]$. This necessitates the optimization of the system by testing several combinations of promoters and/or IRES and the order of genes within the expression cassette [46]. Furthermore, IRES activity can be affected by cell type, and variable expression can be observed in the downstream coding sequence [50]. 
2A/2A-like sequences have been used in a range of heterologous expression systems because of their cleavage capacity. These systems include viruses [51], yeasts [52,53], fungi [54-56], insect cells [57,58], plants [59], human HTK-143 cells [9], rabbit reticulocytes [60], HeLa cells [61], CHO cells [62], HEK293 cells [63], algae [64], and other animals [65-67].

In yeasts, more than two 2A sequences have been used to co-express proteins from the same vector. As seen in [68] and [69], three proteins were produced using this strategy in S. cerevisiae. Surprisingly, up to nine proteins have been linked and successfully cotranslated and separated with 2A sequences in the yeast Pichia pastoris [70].

Researchers have also attempted to use $2 \mathrm{~A}$ for multi-gene transformation in staple crops $[71,72]$. They can also be used for gene fusion, as seen in tomatoes, potatoes, and others $[73,74]$.

To construct the co-expression vectors, the $2 \mathrm{~A} / 2 \mathrm{~A}$-like sequences are usually incorporated into an adenovirus [75], adeno-associated virus (AAV) [12], retrovirus [76], lentivirus [77,78], or plasmid vector [79,80]. Many other biotechnological applications that depend on the co-expression of multiple genes use 2A/2A-like sequences, e.g., the production of antibodies and antigens that can be used in vaccine production [80-85], observation of chromatin dynamics and genome (DNA and RNA) editing in the application of cell/gene therapies [78,79,86-90], and development of optogenetic tools [91-93]. More examples of viral 2As applications can be found in [94].

\section{Conclusions}

In this article, we reviewed the $2 \mathrm{~A} / 2 \mathrm{~A}$-like sequence distribution of viruses and described the occurrence of these motifs in viral species where these sequences have not been previously reported. These findings need to be confirmed through in vitro tests to verify they are active $2 \mathrm{~A}$-like sequences.

Because of its cleavage function, the $2 \mathrm{~A} / 2 \mathrm{~A}$-like sequences appear to directly affect the complexity of the viral genome, which plays a decisive role in viral evolution. Additionally, they are excellent alternatives for developing new biotechnological tools that depend on the expression of multiple products, such as vaccines, transgenic approaches, cell/gene therapy, and optogenetic tools.

Author Contributions: Conceptualization, J.G.S.d.L. and D.C.F.L.; methodology, J.G.S.d.L.; writingoriginal draft preparation, J.G.S.d.L. and D.C.F.L.; writing-review and editing, J.G.S.d.L. and D.C.F.L.; visualization, J.G.S.d.L. and D.C.F.L. All authors have read and agreed to the published version of the manuscript.

Funding: We would like to thank Conselho Nacional de Desenvolvimento Científico e Tecnológico (CNPq) and Coordenação de Aperfeiçoamento de Pessoal de Nível Superior (CAPES) for financial support.

Institutional Review Board Statement: Not applicable.

Informed Consent Statement: Not applicable.

Conflicts of Interest: The authors declare no conflict of interest. The funders had no role in the design of the study; in the collection, analyses, or interpretation of data; in the writing of the manuscript, or in the decision to publish the results.

\section{References}

1. Donnelly, M.L.L.; Hughes, L.E.; Luke, G.; Mendoza, H.; Ten Dam, E.; Gani, D.; Ryan, M.D. The "cleavage" activities of foot-and-mouth disease virus 2A site-directed mutants and naturally occurring "2A-like" sequences. J. Gen. Virol. 2001, 82, 1027-1041. [CrossRef]

2. Luke, G.A.; de Felipe, P.; Lukashev, A.; Kallioinen, S.E.; Bruno, E.A.; Ryan, M.D. Occurrence, function and evolutionary origins of '2A-like' sequences in virus genomes. J. Gen. Virol. 2008, 89, 1036-1042. [CrossRef]

3. Ryan, M.D.; Donnelly, M.; Lewis, A.; Mehrotra, A.P.; Wilkie, J.; Gani, D. A model for nonstoichiometric, cotranslational protein scission in eukaryotic ribosomes. Bioorg. Chem. 1999, 27, 55-79. [CrossRef] 
4. Donnelly, M.L.L.; Luke, G.; Mehrotra, A.; Li, X.; Hughes, L.E.; Gani, D.; Ryan, M.D. Analysis of the aphthovirus 2A/2B polyprotein "cleavage" mechanism indicates not a proteolytic reaction, but a novel translational effect: A putative ribosomal "skip". J. Gen. Virol. 2001, 82, 1013-1025. [CrossRef]

5. Atkins, J.F.; Wills, N.M.; Loughran, G.; Wu, C.Y.; Parsawar, K.; Ryan, M.D.; Wang, C.H.; Nelson, C.C. A case for "StopGo": Reprogramming translation to augment codon meaning of GGN by promoting unconventional termination (Stop) after addition of glycine and then allowing continued translation (Go). RNA 2007, 13, 803-810. [CrossRef]

6. Brown, J.D.; Ryan, M.D. Ribosome "Skipping": "Stop-Carry On" or "StopGo" Translation. In Recoding: Expansion of Decoding Rules Enriches Gene Expression; Atkins, J.F., Gesteland, R.F., Eds.; Springer: New York, NY, USA, 2010; pp. 101-121.

7. de Felipe, P. Skipping the co-expression problem: The new 2A "CHYSEL" technology. Genet. Vaccines Ther. 2004, 2, 1-6. [CrossRef] [PubMed]

8. Ryan, M.D.; King, A.M.Q.; Thomas, G.P. Cleavage of foot-and-mouth disease virus polyprotein is mediated by residues located within a 19 amino acid sequence. J. Gen. Virol. 1991, 72, 2727-2732. [CrossRef]

9. Ryan, M.D.; Drew, J. Foot-and-mouth disease virus 2A oligopeptide mediated cleavage of an artificial polyprotein. EMBO J. 1994, 13, 928-933. [CrossRef] [PubMed]

10. Donnelly, M.L.L.; Gani, D.; Flint, M.; Monaghan, S.; Ryan, M.D. The cleavage activities of aphthovirus and cardiovirus 2A proteins. J. Gen. Virol. 1997, 78, 13-21. [CrossRef]

11. Nibert, M.L. "2A-like" and "shifty heptamer" motifs in penaeid shrimp infectious myonecrosis virus, a monosegmented doublestranded RNA virus. J. Gen. Virol. 2007, 88, 1315-1318. [CrossRef] [PubMed]

12. Lewis, J.E.; Brameld, J.M.; Hill, P.; Barrett, P.; Ebling, F.J.P.; Jethwa, P.H. The use of a viral 2A sequence for the simultaneous over-expression of both the vgf gene and enhanced green fluorescent protein (eGFP) in vitro and in vivo. J. Neurosci. Methods 2015, 256, 22-29. [CrossRef]

13. Doronina, V.A.; de Felipe, P.; Wu, C.; Sharma, P.; Sachs, M.S.; Ryan, M.D.; Brown, J.D. Dissection of a co-translational nascent chain separation event. Biochem. Soc. Trans. 2008, 36, 712-716. [CrossRef]

14. Yang, X.; Cheng, A.; Wang, M.; Jia, R.; Sun, K.; Pan, K.; Yang, Q.; Wu, Y.; Zhu, D.; Chen, S.; et al. Structures and corresponding functions of five types of picornaviral 2A proteins. Front. Microbiol. 2017, 8, 1-14. [CrossRef]

15. Luke, G.A.; Escuin, H.; De Felipe, P.; Ryan, M. 2A to the Fore-Research, Technology and Applications 2A to the Fore-Research, Technology and Applications. Biotechnol. Genet. Eng. Rev. 2009, 26, 223-260. [CrossRef] [PubMed]

16. Luke, G.A.; Pathania, U.S.; Roulston, C.; De Felipe, P.; Ryan, M.D. DxExNPGP-Motives for the motif. In Recent Research Developments in Virology; Research Signpost: Kerala, India, 2014; Volume 9, pp. 25-42.

17. Luke, G.A.; Ryan, M.D. The protein coexpression problem in biotechnology and biomedicine: Virus 2A and 2A-like sequences provide a solution. Future Virol. 2013, 8, 983-996. [CrossRef]

18. Gorbalenya, A.E.; Pringle, F.M.; Zeddam, J.L.; Luke, B.T.; Cameron, C.E.; Kalmakoff, J.; Hanzlik, T.N.; Gordon, K.H.J.; Ward, V.K. The palm subdomain-based active site is internally permuted in viral RNA-dependent RNA polymerases of an ancient lineage. J. Mol. Biol. 2002, 324, 47-62. [CrossRef]

19. Wang, X.; Zhang, J.; Lu, J.; Yi, F.; Liu, C.; Hu, Y. Sequence analysis and genomic organization of a new insect picorna-like virus, Ectropis obliqua picorna-like virus, isolated from Ectropis obliqua. J. Gen. Virol. 2004, 85, 1145-1151. [CrossRef]

20. Wu, C.Y.; Lo, C.F.; Huang, C.J.; Yu, H.T.; Wang, C.H. The complete genome sequence of Perina nuda picorna-like virus, an insect-infecting RNA virus with a genome organization similar to that of the mammalian picornaviruses. Virology 2002, 294, 312-323. [CrossRef] [PubMed]

21. Li, F.; Browning, G.F.; Studdert, M.J.; Crabb, B.S. Equine rhinovirus 1 is more closely related to foot-and-mouth disease virus than to other picornaviruses. Proc. Natl. Acad. Sci. USA 1996, 93, 990-995. [CrossRef] [PubMed]

22. Wutz, G.; Auer, H.; Nowotny, N.; Grosse, B.; Skern, T.; Kuechler, E. Equine rhinovirus serotypes 1 and 2: Relationship to each other and to aphthoviruses and cardioviruses. J. Gen. Virol. 1996, 77, 1719-1730. [CrossRef] [PubMed]

23. Lindberg, A.M.; Johansson, S. Phylogenetic analysis of Ljungan virus and A-2 plaque virus, new members of the Picornaviridae. Virus Res. 2002, 85, 61-70. [CrossRef]

24. Doherty, M.; Todd, D.; McFerran, N.; Hoey, E.M. Sequence analysis of a porcine enterovirus serotype 1 isolate: Relationships with other picornaviruses. J. Gen. Virol. 1999, 80, 1929-1941. [CrossRef] [PubMed]

25. Jones, M.S.; Lukashov, V.V.; Ganac, R.D.; Schnurr, D.P. Discovery of a novel human picornavirus in a stool sample from a pediatric patient presenting with fever of unknown origin. J. Clin. Microbiol. 2007, 45, 2144-2150. [CrossRef]

26. Hagiwara, K.; Kobayashi, J.; Tomita, M.; Yoshimura, T. Nucleotide sequence of genome segment 5 from Bombyx mori cypovirus 1. Arch. Virol. 2001, 146, 181-187. [CrossRef]

27. Yang, H.; Makeyev, E.V.; Kang, Z.; Ji, S.; Bamford, D.H.; Van Dijk, A.A. Cloning and sequence analysis of dsRNA segments 5, 6 and 7 of a novel non-group A, B, C adult rotavirus that caused an outbreak of gastroenteritis in China. Virus Res. 2004, 106, 15-26. [CrossRef]

28. Zell, R.; Delwart, E.; Gorbalenya, A.E.; Hovi, T.; King, A.M.Q.; Knowles, N.J.; Lindberg, A.M.; Pallansch, M.A.; Palmenberg, A.C.; Reuter, G.; et al. ICTV virus taxonomy profile: Picornaviridae. J. Gen. Virol. 2017, 98, 2421-2422. [CrossRef] [PubMed]

29. Hughes, P.J.; Stanway, G. The 2A proteins of three diverse picornaviruses are related to each other and to the H-rev107 family of proteins involved in the control of cell proliferation. J. Gen. Virol. 2000, 81, 201-207. [CrossRef] [PubMed] 
30. Walter, C.T.; Pringle, F.M.; Nakayinga, R.; De Felipe, P.; Ryan, M.D.; Ball, L.A.; Dorrington, R.A. Genome organization and translation products of Providence virus: Insight into a unique tetravirus. J. Gen. Virol. 2010, 91, 2826-2835. [CrossRef] [PubMed]

31. de Lima, J.G.S.; Teixeira, D.G.; Freitas, T.T.; Lima, J.P.M.S.; Lanza, D.C.F. Evolutionary origin of 2A-like sequences in Totiviridae genomes. Virus Res. 2019, 259, 1-9. [CrossRef] [PubMed]

32. Poulos, B.T.; Tang, K.F.J.; Pantoja, C.R.; Bonami, J.R.; Lightner, D.V. Purification and characterization of infectious myonecrosis virus of penaeid shrimp. J. Gen. Virol. 2006, 87, 987-996. [CrossRef]

33. Zhai, Y.; Attoui, H.; Mohd Jaafar, F.; Wang, H.-Q.; Cao, Y.-X.; Fan, S.-P.; Sun, Y.-X.; Liu, L.-D.; Mertens, P.P.C.; Meng, W.-S.; et al. Isolation and full-length sequence analysis of Armigeres subalbatus totivirus, the first totivirus isolate from mosquitoes representing a proposed novel genus (Artivirus) of the family Totiviridae. J. Gen. Virol. 2010, 91, 2836-2845. [CrossRef]

34. Isawa, H.; Kuwata, R.; Hoshino, K.; Tsuda, Y.; Sakai, K.; Watanabe, S.; Nishimura, M.; Satho, T.; Kataoka, M.; Nagata, N.; et al. Identification and molecular characterization of a new nonsegmented double-stranded RNA virus isolated from Culex mosquitoes in Japan. Virus Res. 2011, 155, 147-155. [CrossRef]

35. Wu, Q.; Luo, Y.; Lu, R.; Lau, N.; Lai, E.C.; Li, W.X.; Ding, S.W. Virus discovery by deep sequencing and assembly of virus-derived small silencing RNAs. Proc. Natl. Acad. Sci. USA 2010, 107, 1606-1611. [CrossRef] [PubMed]

36. Virol, A.; Mor, S.K.; Benjamin, N.; Phelps, D. Molecular detection of a novel totivirus from golden shiner (Notemigonus crysoleucas) baitfish in the USA. Arch. Virol. 2016. [CrossRef]

37. Danielle, M.; Dantas, A.; Henrique, G.; Cavalcante, O.; Oliveira, R.A.C.C.; Lanza, D.C.F.F.; Dantas, M.D.A.; Cavalcante, G.H.O.; Oliveira, R.A.C.C.; Lanza, D.C.F.F. New insights about ORF1 coding regions support the proposition of a new genus comprising arthropod viruses in the family Totiviridae. Virus Res. 2016, 211, 159-164. [CrossRef]

38. Modrow, S.; Falke, D.; Truyen, U.; Schätzl, H. How Do Mutations Lead to the Emergence of Novel Viruses? Springer: Berlin/Heidelberg, Germany, 2013; Volume 9783642207, ISBN 978-3-642-20717-4.

39. Orton, R.J.; Wright, C.F.; King, D.P.; Haydon, D.T. Estimating viral bottleneck sizes for FMDV transmission within and between hosts and implications for the rate of viral evolution. Interface Focus 2019, 10. [CrossRef] [PubMed]

40. Khodamoradi, S.; Shenagari, M.; Kheiri, M.T.; Sabahi, F.; Jamali, A.; Heidari, A.; Ashrafkhani, B. IRES-based co-expression of influenza virus conserved genes can promote synergistic antiviral effects both in vitro and in vivo. Arch. Virol. 2018, 163, 877-886. [CrossRef] [PubMed]

41. Akiyoshi, S.; Ishii, T.; Bai, Z.; Mombaerts, P. Subpopulations of vomeronasal sensory neurons with coordinated coexpression of type 2 vomeronasal receptor genes are differentially dependent on Vmn2r1. Eur. J. Neurosci. 2018, 47, 887-900. [CrossRef]

42. Zhang, K.; Su, L.; Duan, X.; Liu, L.; Wu, J. High-level extracellular protein production in Bacillus subtilis using an optimized dual-promoter expression system. Microb. Cell Fact. 2017, 16, 32. [CrossRef] [PubMed]

43. Bayat, H.; Hossienzadeh, S.; Pourmaleki, E.; Ahani, R.; Rahimpour, A. Evaluation of different vector design strategies for the expression of recombinant monoclonal antibody in CHO cells. Prep. Biochem. Biotechnol. 2018, 48, 160-164. [CrossRef]

44. Takahashi, K.; Yamanaka, S. Induction of Pluripotent Stem Cells from Mouse Embryonic and Adult Fibroblast Cultures by Defined Factors. Cell 2006, 126, 663-676. [CrossRef] [PubMed]

45. Tang, W.; Ehrlich, I.; Wolff, S.B.E.; Michalski, A.M.; Wölfl, S.; Hasan, M.T.; Lüthi, A.; Sprengel, R. Faithful expression of multiple proteins via 2A-peptide self-processing: A versatile and reliable method for manipulating brain circuits. J. Neurosci. 2009, 29, 8621-8629. [CrossRef] [PubMed]

46. Radcliffe, P.A.; Mitrophanous, K.A. Multiple gene products from a single vector: "Self-cleaving" 2A peptides. Gene Ther. 2004, 11, 1673-1674. [CrossRef]

47. Arbab, A.S.; Yocum, G.T.; Wilson, L.B.; Parwana, A.; Jordan, E.K.; Kalish, H.; Frank, J.A. Comparison of transfection agents in forming complexes with ferumoxides, cell labeling efficiency, and cellular viability. Mol. Imaging 2004, 3, 24-32. [CrossRef] [PubMed]

48. de Felipe, P.; Luke, G.A.; Hughes, L.E.; Gani, D.; Halpin, C.; Ryan, M.D. E unum pluribus: Multiple proteins from a self-processing polyprotein. Trends Biotechnol. 2006, 24, 68-75. [CrossRef]

49. Hellen, C.U.T.; Sarnow, P. Internal ribosome entry sites in eukaryotic mRNA molecules. Genes Dev. 2001, 15, 1593-1612. [CrossRef]

50. Bouabe, H.; Fässler, R.; Heesemann, J. Improvement of reporter activity by IRES-mediated polycistronic reporter system. Nucleic Acids Res. 2008, 36, 1-9. [CrossRef]

51. Momose, F.; Morikawa, Y. Polycistronic expression of the influenza A virus RNA-dependent RNA polymerase by using the Thosea asigna virus 2A-like self-processing sequence. Front. Microbiol. 2016, 7, 1-13. [CrossRef]

52. Sun, Y.F.; Lin, Y.; Zhang, J.H.; Zheng, S.P.; Ye, Y.R.; Liang, X.X.; Han, S.Y. Double Candida antarctica lipase B co-display on Pichia pastoris cell surface based on a self-processing foot-and-mouth disease virus 2A peptide. Appl. Microbiol. Biotechnol. 2012, 96, 1539-1550. [CrossRef] [PubMed]

53. Wang, S.; Yao, Q.; Tao, J.; Qiao, Y.; Zhang, Z. Co-ordinate expression of glycine betaine synthesis genes linked by the FMDV 2A region in a single open reading frame in Pichia pastoris. Appl. Microbiol. Biotechnol. 2007, 77, 891-899. [CrossRef]

54. Subramanian, V.; Schuster, L.A.; Moore, K.T.; Ii, L.E.T.; Baker, J.O.; Wall, T.A.; Vander Linger, J.G.; Himmel, M.E.; Decker, S.R. Biotechnology for Biofuels A versatile 2A peptide - based bicistronic protein expressing platform for the industrial cellulase producing fungus, Trichoderma reesei. Biotechnol. Biofuels 2017, 1-15. [CrossRef]

55. Schuetze, T.; Meyer, V. Polycistronic gene expression in Aspergillus niger. Microb. Cell Fact. 2017, 16, 1-8. [CrossRef] [PubMed] 
56. Li, F.; Liu, Q.; Li, X.; Zhang, C.; Li, J.; Sun, W.; Liu, D.; Xiao, D.; Tian, C. Construction of a new thermophilic fungus Myceliophthora thermophila platform for enzyme production using a versatile 2A peptide strategy combined with efficient CRISPR-Cas9 system. Biotechnol. Lett. 2020, 42, 1181-1191. [CrossRef]

57. Osborn, M.J.; Panoskaltsis-Mortari, A.; McElmurry, R.T.; Bell, S.K.; Vignali, D.A.A.; Ryan, M.D.; Wilber, A.C.; McIvor, R.S.; Tolar, J.; Blazar, B.R. A picornaviral 2A-like sequence-based tricistronic vector allowing for high-level therapeutic gene expression coupled to a dual-reporter system. Mol. Ther. 2005, 12, 569-574. [CrossRef] [PubMed]

58. Schwirz, J.; Yan, Y.; Franta, Z.; Schetelig, M.F. Bicistronic expression and differential localization of proteins in insect cells and Drosophila suzukii using picornaviral 2A peptides. Insect Biochem. Mol. Biol. 2020, 119, 103324. [CrossRef]

59. Zhang, B.; Rapolu, M.; Kumar, S.; Gupta, M.; Liang, Z.; Han, Z.; Williams, P.; Su, W.W. Coordinated protein co-expression in plants by harnessing the synergy between an intein and a viral 2A peptide. Plant Biotechnol. J. 2017, 15, 718-728. [CrossRef]

60. de Felipe, P.; Hughes, L.E.; Ryan, M.D.; Brown, J.D. Co-translational, intraribosomal cleavage of polypeptides by the foot-andmouth disease virus 2A peptide. J. Biol. Chem. 2003, 278, 11441-11448. [CrossRef]

61. de Felipe, P.; Luke, G.A.; Brown, J.D.; Ryan, M.D. Inhibition of 2A-mediated "cleavage" of certain artificial polyproteins bearing N-terminal signal sequences. Biotechnol. J. 2010, 5, 213-223. [CrossRef]

62. Li, Y.; Wang, M.; Wang, T.; Wei, Y.; Guo, X.; Mi, C.; Zhao, C.; Cao, X.; Dou, Y. Effects of different 2A peptides on transgene expression mediated by tricistronic vectors in transfected CHO cells. Mol. Biol. Rep. 2020, 47, 469-475. [CrossRef]

63. Shin, S.; Kim, S.H.; Shin, S.W.; Grav, L.M.; Pedersen, L.E.; Lee, J.S.; Lee, G.M. Comprehensive Analysis of Genomic Safe Harbors as Target Sites for Stable Expression of the Heterologous Gene in HEK293 Cells. ACS Synth. Biol. 2020, 9, 1263-1269. [CrossRef]

64. Rasala, B.A.; Lee, P.A.; Shen, Z.; Briggs, S.P.; Mendez, M.; Mayfield, S.P. Robust expression and secretion of xylanase1 in Chlamydomonas reinhardtii by fusion to a selection gene and processing with the FMDV 2A peptide. PLoS ONE 2012, 7. [CrossRef] [PubMed]

65. Jeong, I.; Kim, E.; Seong, J.Y.; Park, H.C. Overexpression of Spexin 1 in the Dorsal Habenula Reduces Anxiety in Zebrafish. Front. Neural Circuits 2019, 13, 1-8. [CrossRef]

66. Pontes-Quero, S.; Fernández-Chacón, M.; Luo, W.; Lunella, F.F.; Casquero-Garcia, V.; Garcia-Gonzalez, I.; Hermoso, A.; Rocha, S.F.; Bansal, M.; Benedito, R. High mitogenic stimulation arrests angiogenesis. Nat. Commun. 2019, 10. [CrossRef] [PubMed]

67. Wang, Y.; Wang, F.; Xu, S.; Wang, R.; Chen, W.; Hou, K.; Tian, C.; Wang, F.; Zhao, P.; Xia, Q. Optimization of a 2A self-cleaving peptide-based multigene expression system for efficient expression of upstream and downstream genes in silkworm. Mol. Genet. Genomics 2019, 294, 849-859. [CrossRef] [PubMed]

68. Beekwilder, J.; Van Rossum, H.M.; Koopman, F.; Sonntag, F.; Buchhaupt, M.; Schrader, J.; Hall, R.D.; Bosch, D.; Pronk, J.T.; Van Maris, A.J.A.; et al. Polycistronic expression of a $\beta$-carotene biosynthetic pathway in Saccharomyces cerevisiae coupled to $\beta$-ionone production. J. Biotechnol. 2014, 192, 383-392. [CrossRef]

69. Park, M.; Kang, K.; Park, S.; Kim, Y.S.; Ha, S.H.; Lee, S.W.; Ahn, M.J.; Bae, J.M.; Back, K. Expression of serotonin derivative synthetic genes on a single self-processing polypeptide and the production of serotonin derivatives in microbes. Appl. Microbiol. Biotechnol. 2008, 81, 43-49. [CrossRef] [PubMed]

70. Geier, M.; Fauland, P.; Vogl, T.; Glieder, A. Compact multi-enzyme pathways in P. pastoris. Chem. Commun. 2015, 51, 1643-1646. [CrossRef]

71. Park, S.; Kang, K.; Kim, Y.S.; Back, K. Endosperm-specific expression of tyramine N-hydroxycinnamoyltransferase and tyrosine decarboxylase from a single self-processing polypeptide produces high levels of tyramine derivatives in rice seeds. Biotechnol. Lett. 2009, 31, 911-915. [CrossRef]

72. Quilis, J.; López-García, B.; Meynard, D.; Guiderdoni, E.; San Segundo, B. Inducible expression of a fusion gene encoding two proteinase inhibitors leads to insect and pathogen resistance in transgenic rice. Plant Biotechnol. J. 2014, 12, 367-377. [CrossRef]

73. Yeo, E.T.; Kwon, H.B.; Han, S.E.; Lee, J.T.; Ryu, J.C.; Byun, M.O. Genetic engineering of drought resistant potato plants by introduction of the trehalose-6-phosphate synthase (TPS1) gene from Saccharomyces cerevisiae. Mol. Cells 2000, 10, $263-268$.

74. Ralley, L.; Enfissi, E.M.A.; Misawa, N.; Schuch, W.; Bramley, P.M.; Fraser, P.D. Metabolic engineering of ketocarotenoid formation in higher plants. Plant J. 2004, 39, 477-486. [CrossRef]

75. Chu, V.T.; Weber, T.; Wefers, B.; Wurst, W.; Sander, S.; Rajewsky, K.; Kühn, R. Increasing the efficiency of homology-directed repair for CRISPR-Cas9-induced precise gene editing in mammalian cells. Nat. Biotechnol. 2015, 33, 543-548. [CrossRef] [PubMed]

76. Browne, E.P. An Interleukin-1 Beta-Encoding Retrovirus Exhibits Enhanced Replication In Vivo. J. Virol. 2015, 89, 155-164. [CrossRef] [PubMed]

77. Yi, G.; Choi, J.G.; Bharaj, P.; Abraham, S.; Dang, Y.; Kafri, T.; Alozie, O.; Manjunath, M.N.; Shankar, P. CCR5 gene editing of resting CD4+ T cells by transient ZFN expression from HIV envelope pseudotyped nonintegrating lentivirus confers HIV-1 resistance in humanized mice. Mol. Ther.-Nucleic Acids 2014, 3, 1-10. [CrossRef]

78. Peng, Y.; Yang, T.; Tang, X.; Chen, F.; Wang, S. Construction of an Inducible CRISPR/Cas9 System for CXCR4 Gene and Demonstration of its Effects on MKN-45 Cells. Cell Biochem. Biophys. 2020, 78, 23-30. [CrossRef]

79. Fang, Y.; Stroukov, W.; Cathomen, T.; Mussolino, C. Chimerization enables gene synthesis and lentiviral delivery of customizable tale-based effectors. Int. J. Mol. Sci. 2020, 21, 795. [CrossRef]

80. Mizote, Y.; Masumi-Koizumi, K.; Katsuda, T.; Yamaji, H. Production of an antibody Fab fragment using 2A peptide in insect cells. J. Biosci. Bioeng. 2020, 130, 205-211. [CrossRef] 
81. Arevalo-Villalobos, J.I.; Govea-Alonso, D.O.; Bañuelos-Hernández, B.; González-Ortega, O.; Zarazúa, S.; Rosales-Mendoza, S. Inducible expression of antigens in plants: A study focused on peptides related to multiple sclerosis immunotherapy. J. Biotechnol. 2020, 318, 51-56. [CrossRef] [PubMed]

82. Chen, T.H.; Hu, C.C.; Liao, J.T.; Lee, Y.L.; Huang, Y.W.; Lin, N.S.; Lin, Y.L.; Hsu, Y.H. Production of Japanese encephalitis virus antigens in plants using bamboo mosaic virus-based vector. Front. Microbiol. 2017, 8, 1-12. [CrossRef] [PubMed]

83. Lin, Y.; Hung, C.Y.; Bhattacharya, C.; Nichols, S.; Rahimuddin, H.; Kittur, F.S.; Leung, T.C.; Xie, J. An effective way of producing fully assembled antibody in transgenic tobacco plants by linking heavy and light chains via a self-cleaving 2a peptide. Front. Plant Sci. 2018, 9, 1-11. [CrossRef]

84. Chen, L.; Yang, X.; Luo, D.; Yu, W. Efficient Production of a Bioactive Bevacizumab monoclonal antibody using the 2A self-cleavage peptide in transgenic rice callus. Front. Plant Sci. 2016, 7, 1-12. [CrossRef]

85. Monreal-Escalante, E.; Bañuelos-Hernández, B.; Hernández, M.; Fragoso, G.; Garate, T.; Sciutto, E.; Rosales-Mendoza, S. Expression of Multiple Taenia Solium Immunogens in Plant Cells Through a Ribosomal Skip Mechanism. Mol. Biotechnol. 2015, 57, 635-643. [CrossRef]

86. Jin, S.; Yang, C.; Huang, J.; Liu, L.; Zhang, Y.; Li, S.; Zhang, L.; Sun, Q.; Yang, P. Conditioned medium derived from FGF-2modified GMSCs enhances migration and angiogenesis of human umbilical vein endothelial cells. Stem Cell Res. Ther. 2020, 11, 1-12. [CrossRef] [PubMed]

87. Knoll, A.; Kankowski, S.; Schöllkopf, S.; Meier, J.C.; Seitz, O. Chemo-biological mRNA imaging with single nucleotide specificity. Chem. Commun. 2019, 55, 14817-14820. [CrossRef] [PubMed]

88. Quenneville, S.; Labouèbe, G.; Basco, D.; Metref, S.; Viollet, B.; Foretz, M.; Thorens, B. Hypoglycemia Sensing Neurons of the Ventromedial Hypothalamus Require AMPK-Induced Txn2 Expression But Are Dispensable For Physiological Counterregulation. Diabetes 2020, db200577. [CrossRef]

89. Shibuta, M.K.; Matsuoka, M.; Matsunaga, S. 2a Peptides Contribute To the Co-Expression of Proteins for Imaging and Genome Editing. Cytologia 2019, 84, 107-111. [CrossRef]

90. Sinha, D.; Steyer, B.; Shahi, P.K.; Mueller, K.P.; Valiauga, R.; Edwards, K.L.; Bacig, C.; Steltzer, S.S.; Srinivasan, S.; Abdeen, A.; et al. Human iPSC Modeling Reveals Mutation-Specific Responses to Gene Therapy in a Genotypically Diverse Dominant Maculopathy. Am. J. Hum. Genet. 2020, 107, 278-292. [CrossRef] [PubMed]

91. Kawano, F.; Okazaki, R.; Yazawa, M.; Sato, M. A photoactivatable Cre-loxP recombination system for optogenetic genome engineering. Nat. Chem. Biol. 2016, 12, 1059-1064. [CrossRef] [PubMed]

92. Krishnamurthy, V.V.; Khamo, J.S.; Mei, W.; Turgeon, A.J.; Ashraf, H.M.; Mondal, P.; Patel, D.B.; Risner, N.; Cho, E.E.; Yang, J.; et al. Reversible optogenetic control of kinase activity during differentiation and embryonic development. Development 2016, 143, 4085-4094. [CrossRef]

93. Taslimi, A.; Zoltowski, B.; Miranda, J.G.; Pathak, G.P.; Hughes, R.M.; Tucker, C.L. Optimized second-generation CRY2-CIB dimerizers and photoactivatable Cre recombinase. Nat. Chem. Biol. 2016, 12, 425-430. [CrossRef]

94. Luke, G.A.; Ryan, M.D. Therapeutic applications of the 'NPGP' family of viral 2As. Rev. Med. Virol. 2018, 28, 1-12. [CrossRef] [PubMed] 